\title{
Observação e Design-Based-Research em contextos online
}

\author{
Alda Pereira ${ }^{1}$, Teresa Cardoso', Vera Monteiro¹ e Cândida Pombo ${ }^{1}$ \\ 'LE@D, Laboratório de Educação a Distância e eLearning, Universidade \\ Aberta, Portugal \\ alda.pereira@uab.pt | https://orcid.org/0000-0002-9192-0835 | teresa.cardoso@uab.pt | \\ https://orcid.org/0000-0002-7918-2358 | vcmonteiro@lead.uab.pt | https://orcid.org/0000- \\ 0002-3834-7312 | candidaperpetua@gmail.com | https://orcid.org/0000-0001-6648-7390
}

\begin{abstract}
Resumo: Este capítulo tem como objetivo apresentar dois estudos realizados com recurso à metodologia de Design-Based Research. Estas investigações, com propósitos diferentes, têm em comum o facto de terem sido realizadas inteiramente em contextos online. Procura-se, na descrição feita, relatar sumariamente as fases de cada estudo, os métodos de recolha de dados e a análise realizada no decurso dos processos investigativos e no final dos mesmos. Por terem sido realizados em ambientes virtuais, foram colocados novos desafios no concernente à observação. Equacionamos, por isso, essa problemática e referimos o modo como foi feita a observação em ambos os estudos. Tendo em vista a realização de estudos semelhantes em outros contextos online, elucidamos algumas implicações que emergiram das investigações, nomeadamente sobre a importância da observação como uma técnica qualitativa de recolha de dados e de que modo permite ao investigador aceder às diferentes dimensões do design em estudo.
\end{abstract}

Palavras Chave: Educação; Design-Based Research; Investigação em ambientes virtuais; Design intervencionista; Observação participante.

\section{Introdução}

Este capítulo incide sobre a utilização da metodologia Design-Based Research (DBR) em contextos online e, em particular, sobre a importância da observação. Sendo esta abordagem centrada na investigação em contextos reais, a observação participante é simultaneamente um método e um instrumento de recolha de dados incontornável.

Todavia, a sua utilização em contextos online acarreta outros desafios. Os ambientes virtuais impõem características diferentes à observação, dada a ausência de interação física. Por conseguinte, entendemos necessário refletir sobre esta problemática. Procurase, então, a partir de dois estudos realizados, com caraterísticas diferentes, equacionar de que forma a observação pode ser usada em investigações desta natureza, realizadas em contextos virtuais.

Num primeiro momento, caracteriza-se, de forma sintética, a abordagem DBR, os modelos usados nos dois estudos e os participantes nos mesmos, sendo de assinalar que em ambos se tratou de uma amostra por conveniência. Num segundo ponto, problematiza-se a observação em ambientes virtuais, concretizando depois os instrumentos e técnicas usadas nos estudos referidos e de que forma a observação foi um método de recolha de dados decisivo. Num terceiro ponto, partindo do facto de que uma investigação DBR gera uma multiplicidade de dados, de diferente natureza, referimos os métodos usados de análise de dados, particularizando o modo como a observação contribuiu direta e indiretamente para a respetiva análise e a sua importância na triangulação dos dados.

Por fim, são apresentadas algumas sugestões relativas ao uso de DBR em contextos online. 


\subsection{DBR: características essenciais de uma metodologia plural}

A metodologia de Design-Based-Research (DBR), inspirada no desafio de Brown (1992) de design experimentation, como alternativa aos estudos laboratoriais, tem conhecido uma crescente adesão, pela sua natureza, assente na experimentação de um design intervencionista, in situ, tendo em vista desenvolver teorias que tivessem em conta as múltiplas interações em contextos sociais reais.

O design é revisto e melhorado através de uma série de iterações sucessivas, determinadas pela análise e avaliação da fase anterior e em função das conjeturas iniciais. Esta análise e permanente revisão requer um envolvimento direto na implementação da intervenção, onde a observação e o registo de dados oriundos de várias fontes são passos fulcrais. As iterações permitem ir melhorando a intervenção, testar e procurar as melhores soluções e produzir princípios e teorias que possam ser úteis a outros investigadores (Barab, 2004).

Embora existam várias perspetivas sobre a DBR (Bell, 2004), e o desenvolvimento do estudo possa contemplar diferentes fases, como a seguir se explicita, vários traços essenciais caracterizam esta metodologia (Wang \& Hannafin, 2005): i) pragmática, ii) fundamentada, iii) interativa e flexível, iv) integrativa, e v) contextualizada. Pragmática, porque procura resolver problemas, através do design e implementação de intervenções, refinando os princípios do design do processo e procurando alargar a teoria. Fundamentada, não só porque o design é desenvolvido e implementado com base em teorias, investigações e práticas relevantes, como também se alicerça no conhecimento profundo dos contextos reais de atuação. Interativa, porque, tendo em conta a complexidade dos contextos reais e a dinâmica entre teoria e prática, é desenvolvida com a participação ativa de investigadores e dos participantes no terreno, quer os profissionais, quer os sujeitos na intervenção. E flexível, porque o plano de investigação vai sendo (re)desenhado em função dos resultados intermédios e parcelares. Integrativa, porque se socorre de uma variedade de estratégias e instrumentos de investigação, procurando abranger a multiplicidade de fatores, sendo a triangulação um elemento vital na análise e discussão dos dados e resultados. Finalmente, contextualizada, porque os resultados obtidos se situam num dado contexto real, sendo os princípios ou teorias emergentes válidos em função dos contextos de intervenção (Amiel \& Reeves, 2008). Como tal, as conclusões devem ser tomadas como inspiradoras para outros investigadores e profissionais, ao invés de princípios ou teorias em abstrato.

\subsubsection{Etapas ou fases do processo de investigação DBR}

Apesar do aumento do número de investigações que se reclamam da metodologia de Design-Based Research (Anderson \& Shattuck, 2012; Zheng, 2015), não há um consenso sobre as fases ou etapas do processo de investigação. Amiel e Reeves (2008) traçam um quadro geral: partindo da análise de problemas no terreno são delineados ciclos iterativos de testagem e refinamento, com vista à melhoria da solução desenhada e à produção de princípios de design. Segundo estes autores, o objetivo principal é construir uma forte relação entre a investigação e os problemas reais.

Um dos princípios primordiais da DBR é a iteração sucessiva, de modo a obter as melhores soluções e produzir princípios que possam ser úteis a outros investigadores e intervenientes no terreno, mas não se trata de avaliar um novo produto ou tecnologia.

Shattuck e Anderson (2013) advogam, por sua vez, uma série de etapas condensadas, começando por, face ao problema, realizar uma análise do contexto e exploração de literatura e práticas relevantes de outros estudos, a que se segue a construção de um design de intervenção e respetiva implementação com sucessivas interações, terminando com uma fase de reflexão e avaliação. Já Bannan-Ritland (2003) propõe uma framework para o desenvolvimento da investigação no quadro da Design-Based Research, correspondendo, na verdade, mais a um programa de investigação do que a uma investigação isolada. Este modelo, socialmente construído e contextualmente situado, 
emergiu de uma investigação realizada e consta de quatro fases: (1) Exploração informada; (2) Implementação; (3) Avaliação do impacte local; e (4) Avaliação do impacte global.

Com diferentes caraterísticas e focos de investigação, situamos, de seguida, dois estudos que adotaram a metodologia DBR. O primeiro, intitulado "Recriar Espaços e Ambientes de Aprendizagem: uma nova perspetiva sobre as comunidades virtuais de aprendizagem para jovens" (REAA), no âmbito da aprendizagem informal, centrou-se na indução e dinamização de uma comunidade online, com propósitos educativos na área da física e química, identificando o valor que a participação na comunidade tem para os seus membros (alunos e professores), o que os impele a participarem e que constrangimentos enfrentam (Monteiro, 2013).

O segundo, numa vertente de aprendizagem formal, "Mobile learning e Educação em línguas: contributos para a aprendizagem do Inglês no Ensino Superior online" (MLEL), procurou precisamente averiguar os contributos que o mlearning pode conferir à educação em línguas, em particular do inglês, no ensino superior online (Pombo, 2019).

Embora ambos traduzam inovações educacionais, vemos que o primeiro procurou congregar alunos, professores e investigadores, de forma livre e opcional, em torno de uma área científica, ao passo que o segundo traduziu uma inovação a nível instrucional, recorde-se, no ensino superior online de inglês língua estrangeira. Ambos partilham de uma visão intervencionista da investigação em Educação e inserem-se nas novas configurações da Sociedade em Rede, onde as tecnologias fazem parte do quotidiano e configuram novos espaços e ferramentas intelectuais de acesso, produção e disseminação dos saberes (Castells, 2001). E ambos partilham da conceção de que a DBR é particularmente adequada à intervenção na prática, contribuindo o design para a construção de ecologias de aprendizagem (Cobb, Confrey, diSessa, Lehrer, \& Schauble, 2003).

De acordo com os respetivos objetivos, os dois estudos partiram de premissas teóricas diferentes e desenvolveram-se segundo etapas inspiradas em autores diferentes, que a seguir se explicitam (cf. respetivamente, Figuras 1 e 2, e, ainda, para maior detalhe, Anexos 1 e 2). O primeiro inspirou-se no modelo de Shattuck e Anderson (2013), antes referido, e o segundo no proposto pelos mesmos autores, complementado pelo de Amiel e Reeves (2008), também mencionado.

No estudo 1 (REAA), a dinâmica das sucessivas iterações, em estreita articulação com os seus membros, foi ao encontro do que Barab, Schatz e Scheckler (2004) preconizam sobre os aspetos essenciais do design de comunidades online: i) uma abordagem do projeto coparticipativa e coevolutiva com os seus utilizadores; ii) preferência por uma interface minimalista em oposição a espaços muito desenhados; iii) as melhorias são feitas de forma incremental através do feedback e reações dos membros; iv) o projeto evolui de acordo com as necessidades e agendas dos participantes.

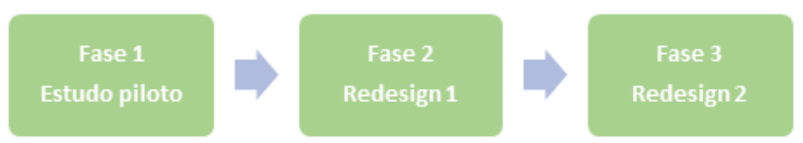

Fig. 1. REEA: fases do estudo

Fonte: as autoras 
No estudo 2 (MLEL), o desenho global da investigação foi enquadrado nos princípios de Collins (1992 apud Kolmos, 2015, p.3): i) a investigação DBR na globalidade, a nível macro; ii) cada uma das iterações a nível meso, conducente a princípios de desenho; iii) os microciclos de Diagnose, Desenho, Implementação e Avaliação (McKenney \& Reeves, 2012), compreendidos em cada iteração, sendo que cada ciclo iterativo informou o ciclo seguinte com princípios de design. A investigação teve início com o primeiro ciclo iterativo a nível meso, isto é, a iteração 0 , seguido de outros dois ciclos iterativos meso, as iterações 1 e 2, cuja avaliação resultou em Princípios de Desenho, ou seja, os resultados obtidos nas três fases da investigação a nível meso. Cada um destes ciclos conteve diversas fases a nível micro, duas na iteração 0 e quatro nos dois ciclos seguintes.

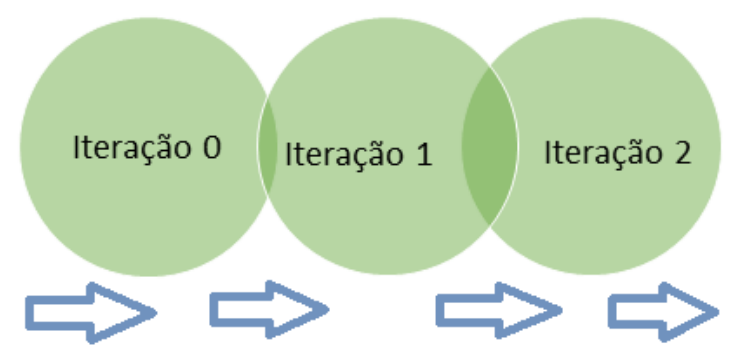

Fig. 2. MLEL: fases do estudo (plano cíclico de iterações)

Fonte: as autoras

\section{Papel do investigador, papéis dos participantes}

Dado os objetivos dos estudos divergirem, sendo um deles caraterizado por um design relativo à construção de uma comunidade aberta e o outro ser dirigido a um nicho particular de ensino formal, numa instituição de ensino superior, o número e o papel dos participantes envolvidos diferiu naturalmente. No caso do estudo REAA, o número de participantes na comunidade de aprendizagem apresentou grande flutuação ao longo do período da investigação, num crescimento orgânico, marcado pela sazonalidade e por alguns acontecimentos desencadeados de forma intencional. No caso do estudo MLEL, 0 número de estudantes envolvidos na investigação foi de 267.

Todavia, numa investigação DBR, a noção de participante ultrapassa o conceito habitual em Educação relativo aos estudantes que são alvo do estudo. A metodologia DBR é de natureza colaborativa, realizada em contexto real. Os participantes são envolvidos no design e na implementação do mesmo (The Design-Based Research Collective, 2003). Tal não significa, contudo, uma atitude menos pró-ativa do investigador. Pelo contrário, o investigador concebe o design e faz a gestão da investigação, sendo também responsável pelo estabelecimento das relações de parceria com os participantes. E, nesta parceria, ao longo da investigação, o investigador vai também apreendendo o contexto. Quando se trata de uma investigação numa situação de ensino formal, o professor (ou os professores) titular(es) da respetiva disciplina é um participante da própria equipa de investigação. Os objetivos da investigação e o design inicial a implementar são aspetos negociados e acordados desde o início com o investigador, alargando-se a colaboração às fases subsequentes. Tal foi o caso no estudo MLEL. Na Iteração 0 (Zero), o trabalho de campo foi realizado pela investigadora; nas Iterações 1 e 2, os Desenhos das iterações foram realizados em estreita colaboração com a Professora-Tutora e a Professora-Orientadora.

No caso do estudo REAA, a investigadora desempenhou a tripla condição de investigadora, responsável pelo design, de administradora da plataforma e de participante, na sua qualidade de professora na área científica da comunidade. Mas, no próprio decurso do processo, emergiram participantes da comunidade que constituíram uma "equipa" dinamizadora da própria comunidade, um grupo nuclear, tal como ocorre em geral nas comunidades de prática, movendo-se os restantes participantes nas periferias. 
Este grupo nuclear era constituído por 4 professores, 4 alunos e a própria investigadora. Várias decisões relativas à alteração do design, nomeadamente de atividades de dinamização da comunidade, foram tomadas por este grupo nuclear.

\subsection{Observação: natureza e características em contextos online}

Nos contextos de investigação online não há uma relação física direta com os participantes num estudo. Nestes contextos, a observação enquanto método e técnica de recolha de dados apresenta características que a diferenciam em muitos aspetos da observação em estudos etnográficos ou antropológicos em contextos presenciais.

Um dos primeiros aspetos diz respeito à caracterização do contexto, diferente dos contextos naturalistas onde ocorrem outros estudos inspirados pela DBR. Este contexto, apelidado de virtual, é na verdade um contexto real, onde se movem os participantes, mas que foge à observação direta (Mann \& Stewart, 2000) - ou a limitam em grande parte - de comportamentos físicos, como linguagem corporal e/ou facial, espacial, quanto aos posicionamentos relativos entre os vários participantes, e extralinguísticos, tais como ritmo do discurso, tonalidade, pausas, interrupções, etc. Apenas em situações de interação síncrona, ou de registos vídeo, é possível observar alguns destes aspetos. Porém, a observação efetuada, mesmo nestes casos, é mediada tecnologicamente: no primeiro caso pela interação homem-máquina e, no segundo, pela seleção feita através da câmara. Estas limitações impossibilitam uma observação direta de comportamentos grupais, nos casos em que as interações entre os membros do grupo são importantes para o estudo em foco. Mesmo comportamentos e interações observados em ambientes imersivos, como - Second Life, correm o risco de enviesamento pela adoção de identidades específicas pelos participantes - a menos que o foco do estudo seja analisar essas próprias identidades. Resta, em grande medida, a observação que incide sobre o discurso verbal, quer seja sobre relatos, quer produções num dado ambiente, quer no que se refere à interação entre os participantes numa dada discussão, seja ela síncrona ou assíncrona. No caso do discurso produzido num espaço de interação assíncrono, o uso de expressões afetivas ou conativas, ou ainda de emoticons, pode ser tomado em conta na observação de aspetos emocionais ou de outras ocorrências - quer sejam de conflito, de entreajuda ou de apoio.

Mas se, por um lado, a observação online sobre espaços de comunicação assíncrona, sejam eles fóruns de discussão, blogues, redes sociais, ou outros, tem limitações relativamente aos aspetos comportamentais de natureza física, por outro, tem a vantagem de ser escrita. Esta não será de menor importância no caso da posterior análise das interações entre os participantes, pois reduz a possibilidade de a descrição e registo da observação ser já ela imbuída de interpretações, como pode acontecer no caso offline.

Do ponto de vista da relação entre o investigador e o ambiente ou processo a ser sujeito à observação, pode situar-se o papel do investigador num contínuo entre observador participante e observador não participante (Creswell, 2007). No primeiro caso, o observador é um participante ativo do processo em estudo. No segundo, pelo contrário, o investigador é completamente externo ao fenómeno a investigar, é um observador passivo. No caso da metodologia de Design-Based Research, o investigador é um participante do próprio processo em investigação.

Dito de outro modo, o investigador, sendo responsável pelo design criado, pela sua implementação e pela análise e avaliação dos vários ciclos, é por natureza um observador participante. Contudo, de acordo com o foco da sua observação, num dado momento, pode assumir um papel mais passivo, mais distanciado.

Esta modificação no seu papel de observador é ainda mais relevante no caso da DBR realizada num contexto online (Nørskov \& Rask, 2011). Ele pode, por exemplo, quando está a fazer observação sobre as interações entre estudantes num dado fórum, tornar-se um observador passivo - ou melhor, ser um observador silencioso (assumindo uma postura de lurker) - e ir observando o que se passa nesse espaço ao longo de um determinado período. 
Como a forma de comunicação é escrita, o registo automático da comunicação ocorrida facilita a sua invisibilidade como observador. O mesmo se passa quando se trata de observações mediadas por vídeo, pois este está disponível enquanto registo permanente do que ocorreu.

Quanto à forma como a observação é feita, ela pode ser estruturada ou não estruturada (Cohen, Manion, \& Morrisson, 2004), consoante é realizada quando se pretende averiguar da incidência, presença e frequência de um dado elemento, o que exige um guião prévio, fixando as categorias a analisar e criando uma correspondente tipologia de registos. $\mathrm{Ou}$, no caso oposto, a observação é não estruturada, quando se tem em vista observar simplesmente e de modo holístico o que está a acontecer, recolhendo impressões gerais e, por vezes, padrões hipotéticos sobre ocorrências.

Flick (2005, referindo Spradley, 1980) aponta a existência de diversas fases da observação participante: i) observação descritiva, abrangente, sobre o campo a investigar; ii) observação focalizada, com um foco mais restrito sobre processos em análise; iii) observação seletiva, centrada na procura de evidências e de exemplos específicos. No primeiro caso, a observação tende a não ser estruturada, enquanto na observação seletiva esta pode ser efetuada com base num protocolo previamente definido.

A utilização da DBR em contextos online levanta ainda outros desafios quanto à observação. Um deles diz respeito à presença/ausência/acesso a um dado espaço. $\mathrm{Na}$ impossibilidade de "ver in loco", o investigador recorre a técnicas facilitadas pela tecnologia, como por exemplo as de learning analytics. Com estas formas modernas de captar "movimentos invisíveis", pode traçar-se um quadro relativo ao acesso a um dado espaço, à frequência do mesmo e à variabilidade do tipo de recurso ou atividade acedida.

Se nos casos de ferramentas tecnológicas atualmente usadas em elearning é possível fazer essa observação focada na identidade de um dado participante, em situações abertas, como é o caso de redes sociais e de plataformas abertas, essa identificação é problemática. Este tipo de observação recai numa forma de observação indireta. Assim, algumas interrogações subsistem quanto às possibilidades e limites da observação em contextos online. Por exemplo, no que diz respeito à participação de um estudante numa dada atividade, se a sua "voz" não se tiver feito ouvir num debate assíncrono, é viável assumir que ele esteve ausente? Se no caso de uma comunidade online, ou numa sala de aula virtual, não encontramos nenhum indício da sua "presença", é lícito supor que ele se alheou de uma atividade em curso?

\subsection{Instrumentos de recolha de dados e locus da observação}

Do ponto de vista metodológico a DBR é pluralista, isto é, recorre a métodos diversos (The Design-Based Research Collective, 2003), em função do foco de investigação e das necessidades de análise no decorrer do processo, integrando também várias formas e instrumentos de recolha e análise de dados, quer qualitativos quer quantitativos. Podemos, entre outros, enumerar os seguintes: observação no terreno, entrevistas, análise documental, questionários, análise de redes sociais.

Com base em métodos etnográficos podemos exemplificar observações sobre interações (colaborativas ou não), discussões ocorridas, planificações, mecanismos de entreajuda, etc. que ocorrem no contexto em estudo (Brown, 1992). Sintetizamos, em seguida, as diversas técnicas e instrumentos de recolha de dados adotados em cada um dos dois estudos em análise.

No estudo 1 (REAA), foram usadas técnicas de recolha de dados variadas, diretas e indiretas (cf. Quadro 1). 
Quadro 1. REEA: Técnicas e instrumentos usados no estudo

\begin{tabular}{ll}
\hline $\begin{array}{c}\text { Técnicas diretas ou } \\
\text { interativas }\end{array}$ & Instrumento de recolha/registo \\
\hline Observação & Observação dos espaços da \\
participante & -63 -plataforma Ning - dados \\
& estatísticos gerados pelo site, \\
perfis dos membros, participação & nos fóruns, chat com os \\
& membros; emails trocados com \\
& membros da comunidade/registo \\
& - diário do investigador, notas de \\
& campo. Observação do fluxo \\
& comunicativo no Facebook e \\
& Twitter/registo - notas de campo. \\
& \\
Questionários online & LimeSurvey. \\
& \\
Entrevistas & Skype e videoconferência do \\
semiestruturadas & Facebook. Gravadas com MP3 \\
Skype Recorder 3.1.
\end{tabular}

Fonte: as autoras

A observação participante foi a técnica de recolha de dados omnipresente em todo o processo de DBR. Traduziu-se não só no registo sistemático de informação, impressões, ideias e hipóteses no diário do investigador, como também na observação de inscrições deixadas na rede, a exemplo de grafos e analytics, e ainda na observação das interações, via chats e emails, e na observação das discussões ocorridas em fóruns.

Salienta-se, neste ponto, a necessidade de recorrer à observação através de técnicas indiretas, usando ferramentas tecnológicas, no caso o Google Analytics, de modo a obter, no decorrer das diversas fases do estudo, uma perceção do interesse na comunidade, através dos acessos à comunidade e aos seus diversos espaços. Sem a possibilidade de recorrer a ferramentas informáticas para fazer este tipo de observação, teria sido impossível saber, num dado momento, quantos participantes tinham aderido à comunidade e onde se localizavam geograficamente.

Nas técnicas diretas de recolha de dados, observou-se o princípio do consentimento voluntário, tendo os informantes sido esclarecidos de que as informações solicitadas se inscreviam num estudo académico. Por outro lado, foi garantido o anonimato dos respondentes ao questionário e dos entrevistados, bem como a confidencialidade dos dados. No caso dos entrevistados, foi expressamente solicitada e aceite a permissão para a gravação e transcrição, para análise das entrevistas.

No estudo 2 (MLEL) os recursos implementados em cada uma das iterações constituíramse, frequentemente, como instrumentos de recolha de dados, uma vez que a metodologia DBR, direcionada para ambientes digitais, em imersão virtual, funciona como um todo sistémico, flexível e iterativo. 
Sistematizam-se, em seguida, instrumentos de recolha de dados, previstos no delineamento da investigação, e os recursos digitais implementados para aprendizagem com recurso ao mlearning, apps ou learning objects (LO), que se constituíram eles próprios como instrumentos de recolha de dados e avaliação das atividades e que forneceram dados, quer qualitativos, quer quantitativos, sobretudo na iteração 2 (cf. Quadro 2).

Quadro 2. MLEL: Técnicas e instrumentos usados no estudo

\begin{tabular}{|c|c|}
\hline $\begin{array}{l}\text { Técnicas e instrumentos } \\
\text { diretos }\end{array}$ & $\begin{array}{l}\text { Métodos e Instrumentos de } \\
\text { recolha }\end{array}$ \\
\hline $\begin{array}{l}\text { Observação participante } \\
\text { descritiva }\end{array}$ & $\begin{array}{l}\text { Observação no terreno; } \\
\text { Grelhas de recolha de dados. }\end{array}$ \\
\hline $\begin{array}{l}\text { Observação participante } \\
\text { focalizada }\end{array}$ & $\begin{array}{l}\text { Grelhas de recolha de } \\
\text { dados/Notas de Campo. }\end{array}$ \\
\hline Questionários online (4) & $\begin{array}{l}\text { Correio } \\
\text { eletrónico/GoogleDocs. }\end{array}$ \\
\hline $\begin{array}{l}\text { Entrevistas } \\
\text { semiestruturadas (3) }\end{array}$ & Correio eletrónico. \\
\hline $\begin{array}{l}\text { Técnicas e instrumentos } \\
\text { diretos }\end{array}$ & $\begin{array}{l}\text { Métodos e Instrumentos de } \\
\text { recolha }\end{array}$ \\
\hline Observação focalizada & $\begin{array}{l}\text { Grelhas de recolha de } \\
\text { dados/Notas de Campo }\end{array}$ \\
\hline $\begin{array}{l}\text { Recursos/ferramentas } \\
\text { digitais implementados } \\
\text { para aprendizagem }\end{array}$ & $\begin{array}{l}\text { Produção dos estudantes no } \\
\text { Padlet e nos } \\
\text { ActiveTextsBooks. }\end{array}$ \\
\hline
\end{tabular}

Fonte: as autoras

Do ponto de vista ético, os estudantes foram informados pela Professora-Tutora, no início do estudo, de que se tratava de uma investigação. Aos mesmos estudantes foi garantido que a sua colaboração era totalmente anónima e confidencial, pelo que todos os nomes dos intervenientes foram codificados. Acrescente-se que os quatro questionários solicitados aos estudantes incluíam o registo de aceitação prévia de consentimento informado.

\section{Análise de dados}

No estudo 1 (REAA) os dados resultantes da observação foram analisados para fornecer, no seu conjunto, retratos da comunidade sob diferentes perspetivas e a diferentes níveis. Importa salientar que foram determinantes para a seleção de outras técnicas de análise de dados, de forma a aprofundar a análise, tendo em conta a relação com as teorias que enformaram o estudo (Siemens, 2005; Wenger, 1998; Wenger, Trainer, \& Laat, 2011; Engeström, 1999, 2001).

Para proceder à análise de conteúdo do site recorreu-se ao software Cohere, então disponível, gratuito e livre. Selecionámos algumas discussões que, do nosso ponto de vista, melhor ilustravam algumas das dinâmicas emergentes no contexto da comunidade. As conversas foram selecionadas com base em critérios de qualidade científica do conteúdo, diversidade, e quantidade dos participantes que congregaram e dos contributos que receberam. Obtivemos mapas que detalhavam as relações e a qualidade das interações entre os diferentes intervenientes. A análise dos conteúdos partilhados e das 
cadeias de comunicação forneceu pistas acerca da criação de valor da comunidade para os seus membros, que posteriormente conduziram à análise de redes sociais (ARS).

O uso desta técnica recaiu sobre o estudo das interações nos fóruns. Foi feita, para cada fórum analisado, uma análise: i) individual - 0 ator e as suas ligações; ii) grupal - núcleos de atores em que as ligações se estabelecem com maior intensidade; iii) global distribuição das ligações entre todos os atores, evidenciando os mais centrais e periféricos às redes obtidas.

Os dados recolhidos através dos questionários online implementados no estudo (três intercalares e um final, mais detalhado) foram tratados e sujeitos a análise estatística simples. Nas questões que tinham associadas itens de Likert, foram calculados os valores médios das respostas e respetivos desvios padrão; nas restantes questões, foram tratados em termos de frequência das respostas aos vários itens. Dada a natureza qualitativa da investigação, estes dados eram suficientes, pelo que não foi necessário recorrer à análise estatística inferencial.

A análise dos conteúdos das entrevistas aplicadas - distintamente a professores (6) e alunos (6), no final da fase 3 - foi efetuada recorrendo ao software NVivo 10 (QSR). A categorização das unidades de sentido foi efetuada com base num sistema de categorias predefinido pela investigadora. As categorias decorreram das ferramentas e conceções teóricas em investigação. Em particular, a moldura de criação de valor em comunidades e redes (Wenger, Trainer, \& Laat, 2011) para aferir o va lor criado pela comunidade, e a teoria da atividade - $3^{a}$ geração (Engeström, 1999) porque, ao focar-se na interação entre a atividade humana e consciência, proporciona uma moldura de trabalho adequada para compreender a atividade no seu contexto (Jonassen \& Ronrer-Murphy, 1999). Seguiu-se um processo iterativo de aperfeiçoamento da categorização inicial, configurando-se clusters de categorias que se traduziram não só em resultados férteis ao nível das asserções que procurávamos triangular com o questionário final, como também indicaram novas pistas de análise e reflexão teórica.

No estudo 2 (MLEL) a observação participante propiciou também a recolha de dados diversificados e com diferentes propósitos. A sua análise i) consubstanciou o microciclo da Diagnose em cada iteração e informou o respetivo Desenho, com repercussões nas fases de Implementação e Avaliação; ii) permitiu a triangulação metodológica parcial no final de cada iteração, refinando os Princípios de Desenho, através da emergência de padrões; iii) foi decisiva na triangulação final.

Através da observação indireta foi possível fazer a análise da adesão dos estudantes às atividades de mlearning e às diferentes apps, bem como analisar a evolução das suas competências na língua estrangeira (inglês), mormente a nível da produção escrita e oral, de acordo com o QECRL (2001). Por exemplo, os dados dos ficheiros Excel gerados pelos quizzes online (estatísticas do acesso dos estudantes, percentagens alcançadas e repetição dos exercícios para otimização das classificações, espelhadas nos certificados gerados) foram sujeitos a análise estatística simples. Também os dados dos inquéritos por questionário (dois iniciais, numa fase prévia a cada iteração, e dois no final das respetivas avaliações), das secções com questões de carácter fechado, utilizando a escala de Likert, foram sujeitos a análise estatística simples; neste caso, foram calculados os valores médios das respostas, comparativamente aos desvios padrão.

Por sua vez, a observação sobre a forma como os estudantes reagiam e interagiam com as apps, nomeadamente os murais implementados (Padlet e ActiveTextBook), foram cruciais para analisar as competências de língua, reformular as atividades propostas e efetuar o cruzamento com os dados emergentes das notas de campo, entrevistas semiestruturadas e inquéritos por questionário. A título exemplificativo, a análise dos dados recolhidos com as grelhas de observação focada dos Fóruns Professor-Alunos das três turmas (da iteração 2) conduziu a um estudo comparativo entre os valores do número de temas e número de mensagens do Fórum associados às atividades de elearning e os valores registados durante a investigação de mlearning dentro do mesmo horizonte temporal. As notas de campo, de cariz indutivo, deram origem a uma tipologia diversificada 
de observações; porém, destas emergiram igualmente categorias, que sustentaram os padrões dominantes obtidos, reforçando a triangulação de dados.

Também os dados dos questionários implementados, relativos às questões de caráter aberto, foram objeto de uma análise categorial do conteúdo, resultando em tabelas concebidas com esse intuito; neste caso, os dados não estavam pré-categorizados. Já a análise de conteúdo das entrevistas a estudantes, nas iterações 1 e 2, foi efetuada a partir de uma pré-categorização, embora tenham emergido ainda novas categorias. Os resultados de todas as entrevistas foram triangulados com os restantes dados recolhidos e influíram quer no desenho da iteração 2, ainda no decurso da investigação, quer na análise final dos resultados.

\section{Considerações finais}

Das implicações práticas de ambos os estudos, tomados como exemplos para pensar e problematizar a observação e a DBR em contextos online, podemos elencar aplicações para outros contextos. Em particular, inspirando-nos em Monteiro (2013) e sugerindo intervenções ao nível da criação de uma comunidade de aprendizagem num open space, importa: promover oportunidades para interagir com especialistas nos domínios de interesse dos participantes na comunidade; proporcionar o acesso a saberes novos e diferenciadores dos curricula, no sentido de potenciar a literacia científica e satisfazer curiosidades pessoais; fomentar pontos de complementaridade entre o ensino formal e a esfera pessoal; sustentar este tipo de comunidade não na atividade escolar tradicional, mas antes na interface escola-sociedade. Inspirando-nos agora em Pombo (2019) e sugerindo intervenções, no sentido da inovação em mlearning, importa: analisar, de forma aturada, as apps disponíveis para responder a objetivos e conteúdos dos curricula; diversificar os espaços (formais/informais) de intervenção; fazer a ambientação a novos dispositivos; privilegiar microatividades (em detrimento de atividades longas).

Em suma, a concluir, avançamos com diretrizes sintéticas para outros estudos que pretendam adotar a metodologia DBR em contextos online, nomeadamente: as técnicas e os métodos devem ser plurais, portanto, não centrados num único tipo de instrumento (o que é válido quer na recolha, quer na análise dos dados). O investigador em DBR é por natureza um observador participante, mas o facto de a investigação se realizar em contexto online levanta a possibilidade de fazer a observação de modo mais visível ou menos visível para os participantes a observar, sendo frequentemente um observador silencioso. Está, neste caso, a observação de artefactos produzidos ou de interações e comunicações em modo assíncrono, durante um dado período temporal. Assinale-se, por outro lado, a necessidade de, nestes contextos, se recorrer à observação indireta, mediada por dispositivos eletrónicos e/ou formas de fazer o rastreamento dos participantes com recurso a tecnologias disponíveis na Web. Finalmente, a utilização da observação, enquanto método na investigação DBR em contexto online, é um dos traços fundamentais. Feita de forma estruturada ou não estruturada, é uma fonte de inspiração sistemática para alterações do design e até das técnicas de recolha de dados.

\section{Referências}

Alves, J. (2001) (dir.). Quadro Europeu Comum de Referência para as Línguas- aprendizagem, ensino, avaliação. Conselho da Europa. Porto: Edições Asa.

Amiel, T. \& Reeves, T.C. (2008). Design based research and technology: Rethinking technology and the research agenda. Educational Technology \& Society, 11(4), 29-40.

Anderson, T. \& Shattuck (2012). Design-Based Research: A Decade of Progress in Education Research? Educational Researcher, 41(1), 16-25. https://doi.org/10.3102/0013189X11428813

Bannan-Ritland, B. (2003). The Role of Design in Research: The Integrative Learning Design Framework. Educational Researcher, 32(1), 21-24. https://doi.org/10.3102/0013189X032001021 
Barab, S.A. (2004). Using Design to Advance Learning Theory, or Using Advance Design. Educational Technology, May-June, 44(3), 16-19.

Barab, S., Schatz, S., \& Scheckler, R. (2004). Using Activity Theory to Conceptualize Online Community and Using Online Community to Conceptualize Activity Theory. Mind, Culture and Activity, 11(1), 25-47. https://doi.org/10.1207/s15327884mca1101 3

Bell, F. (2004). On the Theoretical Breadth of Design-Based Research in Education. Educational Psychologist, 39(4), 243-253. https://doi.org/10.1207/s15326985ep3904 6

Brown, A.L. (1992). Design Experiments: Theoretical and Methodological Challenges in Creating Complex Interventions in Classroom Settings. The Journal of the Learning Sciences, 2(2), 141-178. https://doi.org/10.1207/s15327809jls0202 2

Castells, M. (2001). A Galáxia Internet - Reflexões sobre Internet, Negócios e Sociedade. Lisboa: Fundação Calouste Gulbenkian.

Cobb, P., Confrey, J., diSessa, A., Lehrer, R., \& Schauble, L. (2003). Design Experiments in Educational Research. Educational Researcher, 32(1), 9-13. https://doi.org/10.3102/0013189X032001009

Cohen, L., Manion, L., \& Morrisson, K. (2004). Research Methods in Education (5th edition). London: Routledge Falmer.

Creswell, J.W. (2007). Qualitative Inquiry Research Design: Choosing Among Five Approaches. USA, Sage Publications.

Engeström, Y. (1999). Innovative learning in work teams: analysing cycles of knowledge creation in practice. In Y. Engeström, R. Miettinen \& R. Punamäki (Eds.), Perspectives on Activity Theory, 377-406. Cambridge: Cambridge University Press.

Engeström, Y. (2001). Expansive Learning at Work: Toward an activity theoretical reconceptualization. Journal of Education and Work, 14(1), 133-156. https://doi.org/10.1080/13639080020028747

Flick, U. (2005). Métodos Qualitativos na Investigação Científica. Lisboa: Monitor.

Jonassen, D., \& Ronrer-Murphy, L. (1999). Activity Theory as a framework for Designing Constructivist Learning Environments. ETR\&D, 47(1), 61-79. https://doi.org/10.1007/BF02299477

Kolmos, A. (2015). Design-based research: Issues in connecting theory, research and practice. In Research in Engineering Education Symposium, 13-15. Aungier St.: Dublin Institute of Technology.

McKenney, S. E., \& Reeves, T. C. (2012). Conducting educational research design: what, why and how. Taylor \& Francis.

Mann, C., \& Stewart, F. (2000). Internet Communication and Qualitative Research: A Handbook for Researching for Researching Online. London: Sage Publications.

Monteiro, V.C. (2013). Recriar espaços e ambientes de aprendizagem: uma nova perspectiva sobre as comunidades virtuais de aprendizagem para jovens (Tese de doutoramento). Universidade Aberta. http://hdl.handle.net/10400.2/2945

Nørskov, S.V., \& Rask, M. (2011). Observation of Online Communities: A Discussion of Online and Offline Observer Roles in Studying Development, Cooperation and Coordination in an Open Source Software Environment. FQS: Forum Qualitative Sozialforschung/Forum Qualitative Social Research, 12(3), setembro. DOI: http://dx.doi.org/10.17169/fqs-12.3.1567

Pombo, C.P. (2019). Mobile learning e educação em línguas: contributos para a aprendizagem do inglês no ensino superior online (Tese de doutoramento). Universidade Aberta. http://hdl.handle.net/10400.2/9035

Siemens, G. (2005). Connectivism: A learning theory for the digital age. International Journal of Instructional Technology and Distance Learning, janeiro.

Shattuck, J., \& Anderson, T. (2013). Using a Design-Based Research Study to Identify Principles for Training Instructors to Teach Online. The International Review of Research in Open and Distributed Learning, 14(5), 1-22. 
The Design-Based Research Collective. (2003). Design-Based Research: An Emerging Paradigm for Educational Inquiry. Educational Researcher, 32(1), 5-8. https://doi.org/10.3102/0013189X032001005

Wang, F., \& Hannafin, M.J. (2005). Design-Based Research and Technology-Enhanced Learning Environments. Educational Technology Research and Development, 53(4), 5-23.

Wenger, E. (1998). Communities of Practice: learning, meaning, and identity. New York: University Press.

Wenger, E., Trainer, B., \& Laat, M.D. (2011). Promoting and assessing value creation in communities and networks: a conceptual framework. Ruud de Moor Centrum. Open Universiteit Nederland.

Zheng, L. (2015). A systematic literature review of design-based research from 2004 to 2013 Journal of Computers in Education, 2(4), 399-420. https://doi.org/10.1007/s40692-015-0036-z

ANEXOS

Anexo 1. REEA: descrição das fases do estudo

\section{EXPLICITAÇÃO DAS FASES DO ESTUDO 1}

FASE 1

Pesquisa e exploração das ferramentas tecnológicas mais adequadas à: configuração do espaço virtual para ancorar a comunidade; configuração da ferramenta escolhida (Ning); implementação de um design exploratório e respetiva análise; primeira divulgação da comunidade.

FASE 2

Redefinição do design da plataforma de suporte: adição de novas funcionalidades (widgets, RSS feeds), organização de novas secções e espaços de discussão; abertura à quase totalidade do conteúdo.

Definição de nova estratégia de dinamização no sentido de incrementar a interação, a partilha de conteúdos e a resposta a solicitações feitas pelos participantes: realização de discussões com especialistas convidados, procurando trazer a expertise à comunidade; as atividades passaram a ser organizadas e dinamizadas por uma equipa nuclear (liderada pela investigadora).

Divulgação em massa da comunidade, criando e difundindo uma newsletter.

A análise desta fase revelou um acréscimo significativo de acessos ao site e aos espaços da comunidade. Todavia, verificou-se que a maior partilha de conteúdos não se refletiu num maior impacte na participação expressa, indicando que ainda não se tinha atingido um nível ótimo de interesse por parte dos participantes.

FASE 3

Novo redesenho do espaço da comunidade, apostando num site mais minimalista, mas com mais informação e orientação aos membros, com um visual mais atrativo (cores, tipo de letra, símbolo da comunidade); organização de vários micro-espaços com separadores, com destaque para uma zona de esclarecimento de dúvidas e outra de contacto com especialistas.

Procedeu-se a um novo sistema de navegação e de localização da informação baseada em tags, de modo a melhorar a navegabilidade e a usabilidade. Foi criada uma página Facebook e uma conta Twitter, alargando os espaços virtuais de encontro dos membros da comunidade. Deu-se início à divulgação direta, via correio eletrónico, junto das escolas e à substituição da newsletter pela difusão de emails com as questões colocadas pelos participantes, com link associado para a resposta. Foram lançados dois concursos (fotografia laboratorial e vídeo) e Webinars trimestrais. A comunidade passou a contar com dois bloggers residentes.

Fonte: Monteiro (2013) 
Anexo 2. MLEL: descrição das fases do estudo (plano cíclico de iterações)

\section{EXPLICITAÇÃO DAS FASES DO ESTUDO 2}

\begin{tabular}{|c|c|}
\hline \multirow[t]{2}{*}{$\begin{array}{l}\text { ITERAÇÃO } \\
0\end{array}$} & $\begin{array}{l}\text { "Exploração Informada", na qual decorreu um } \\
\text { estudo exploratório e analítico, que incidiu no } \\
\text { conhecimento do ambiente e contexto de } \\
\text { aprendizagem e, ainda, na caracterização do público- } \\
\text { alvo da investigação. Incluiu igualmente pesquisa e } \\
\text { estudos analíticos sobre apps disponíveis no mercado } \\
\text { para aprendizagem de línguas estrangeiras (LE) } \\
\text { através de mlearning. }\end{array}$ \\
\hline & $\begin{array}{l}\text { Devido ao seu carácter exploratório, este ciclo foi } \\
\text { composto apenas por duas fases a nível micro: } \\
\text { Diagnose e Avaliação. Com base nesta avaliação foi } \\
\text { possível alavancar princípios de desenho e delinear o } \\
\text { ciclo iterativo seguinte. Teve também o intuito de } \\
\text { conceber estratégias e desenhar atividades a } \\
\text { implementar com recurso ao mlearning, alinhadas ao } \\
\text { contexto virtual onde iria decorrer a intervenção. Para a } \\
\text { efetivação das estratégias a usar foram selecionadas } \\
\text { as apps mais adequadas, tendo sido elaborada uma } \\
\text { proposta de proposta de tabela taxonómica para apps } \\
\text { de aprendizagem de LE com recurso a dispositivos } \\
\text { móveis (DM). }\end{array}$ \\
\hline $\begin{array}{l}\text { ITERAÇÃO } \\
1\end{array}$ & $\begin{array}{l}\text { O Design para a intervenção alicerçou-se na } \\
\text { Diagnose resultante dos Princípios de Desenho da } \\
\text { iteração zero, através da conceção de estratégias } \\
\text { pedagógicas e desenho de atividades conducentes ao } \\
\text { processo de ensinar e aprender inglês a distância, com } \\
\text { recurso ao mlearning através de DM e apps, com vista } \\
\text { a desenvolver as competências preconizadas pelo } \\
\text { currículo programático da UC. Seguiu-se o microciclo } \\
\text { da implementação em ambiente de imersão virtual e } \\
\text { subsequente avaliação. A análise dos dados } \\
\text { recolhidos, após triangulação, propiciou o refinamento } \\
\text { dos princípios de desenho conducentes à iteração } 2 \text {. }\end{array}$ \\
\hline $\begin{array}{l}\text { ITERAÇÃO } \\
2\end{array}$ & $\begin{array}{l}\text { O ciclo iterativo } 2 \text { constituiu-se como um ciclo iterativo } \\
\text { otimizado pela triangulação parcial dos dados } \\
\text { recolhidos e analisados, conducentes ao microciclo de } \\
\text { Diagnose e ao refinamento dos Princípios de Desenho. } \\
\text { À semelhança da iteração anterior, o Desenho estava } \\
\text { alinhado com a caracterização do público-alvo, o } \\
\text { contexto de implementação e a taxonomia de apps } \\
\text { concebida para o efeito. Neste contexto, encetou-se } \\
\text { com um Módulo de ambientação, tendo-se optado por } \\
\text { um mural mais sólido e estruturado do que o da iteração } \\
1 \text {; dividiu-se o plano de aula em microatividades, } \\
\text { propiciou-se follow-up no grupo criado no Facebook } \\
\text { (conforme sugestão de estudantes na iteração anterior) } \\
\text { e reforço positivo através da atribuição de badges. A } \\
\text { implementação foi objeto de reformulação e de } \\
\text { negociação constante, bem como de (co)construção de } \\
\text { conhecimento e conteúdos. A avaliação realizou-se } \\
\text { sobretudo através da observação participante e } \\
\text { focalizada em diversos loci de intervenção. Apps e LO } \\
\text { constituíram-se, igualmente, como instrumentos } \\
\text { indiretos de recolha de dados. A triangulação final } \\
\text { conduziu a } 12 \text { Princípios de Desenho. }\end{array}$ \\
\hline
\end{tabular}

Fonte: Pombo (2019) 


\section{Notas biográficas}

Alda Pereira. Doutorada em Ciências da Educação, Professora Associada aposentada da Universidade Aberta. Dedica-se atualmente à investigação no Laboratório de Educação a Distância e eLearning (LE@D). Lecionou diversas unidades curriculares de graduação e pós-graduação, em regime online, entre as quais algumas dedicadas às metodologias de investigação. Desempenhou diversos cargos e coordenou vários cursos formais, quer de graduação, quer de pós-graduação. Coautora do Modelo Pedagógico Virtual da Universidade Aberta. Tem participado em diversos projetos de investigação, nacionais e internacionais. Autora de várias publicações e artigos, é atualmente editora da Revista de Educação e eLearning (RE@D) e integra vários projetos no LE@D. https://orcid.org/0000-0002-9192-0835

Teresa Cardoso. Docente da Universidade Aberta no Departamento de Educação e Ensino a Distância; leciona em cursos de graduação e pós-graduação, incluindo em unidades curriculares de investigação em educação. É investigadora integrada na UID-FCT no 4372, LE@D, Laboratório de Educação a Distância e eLearning, onde tem colaborado em vários projetos. É formadora acreditada pelo Conselho Científico-Pedagógico da Formação Contínua do Ministério da Educação, autora e editora de publicações, integra comissões científicas/editoriais e tem participado na organização de eventos científicos nacionais e internacionais. Ao nível da investigação, interessa-se pela educação aberta, jogos e aprendizagem móvel ou mobile learning, e TIC em contextos educacionais. http://orcid.org/0000-0002-7918-2358

Vera Monteiro. Doutorada em Educação, especialidade de Ensino a Distância e Elearning, pela Universidade Aberta de Portugal (UAb), em janeiro de 2014. Mestre em Comunicação Educacional Multimédia, desde 2007, pela mesma universidade. Licenciada em Engenharia Química, pelo Instituto Superior Técnico, em 1995. Membro integrado do Laboratório de Educação a Distância (LE@D), da UAb, desde 2014. Experiência como tutora e monitora online, de cursos de 1ำ ciclo, na UAb. Professora de Física e Química do Ensino Básico e Secundário, desde 1993. Interesses de investigação em comunidades virtuais de aprendizagem, teoria da atividade, conectivismo, ensino e aprendizagem das ciências. https://orcid.org/0000-0002-3834-7312

Cândida Perpétua Pombo. Doutorada em Educação pela Universidade Aberta, em 2019. Mestre em Gestão de Sistemas de e-Learning, Universidade Nova de Lisboa. Licenciada em Línguas e Literaturas Modernas (Inglês/Alemão) e em Línguas Modernas (Espanhol/Inglês) pela Universidade de Coimbra. Formadora acreditada pelo Conselho Científico-Pedagógico da Formação Contínua do Ministério da Educação. Investigadora do Laboratório de Educação a Distância (LE@D), da UAb. Professora de Línguas Estrangeiras - Ensino Secundário, requisitada na Direção-Geral da Educação, Direção de Serviços de Desenvolvimento Curricular desde 2017. Interesses de investigação: Mobile learning e gamificação no ensino e aprendizagem das Línguas e metodologia DBR. https://orcid.org/0000-0001-6648-7390 